\title{
ERRATUM
}

\section{Signal analyser on an optical chip}

Christophe Dorrer

Nature Photonics 3, 136-137 (2009), corrected after print 26 March 2009.

In the version of this News \& Views originally published, Figure 1 was missing. It should have appeared as shown below. This has now been corrected in the HTML and PDF versions.
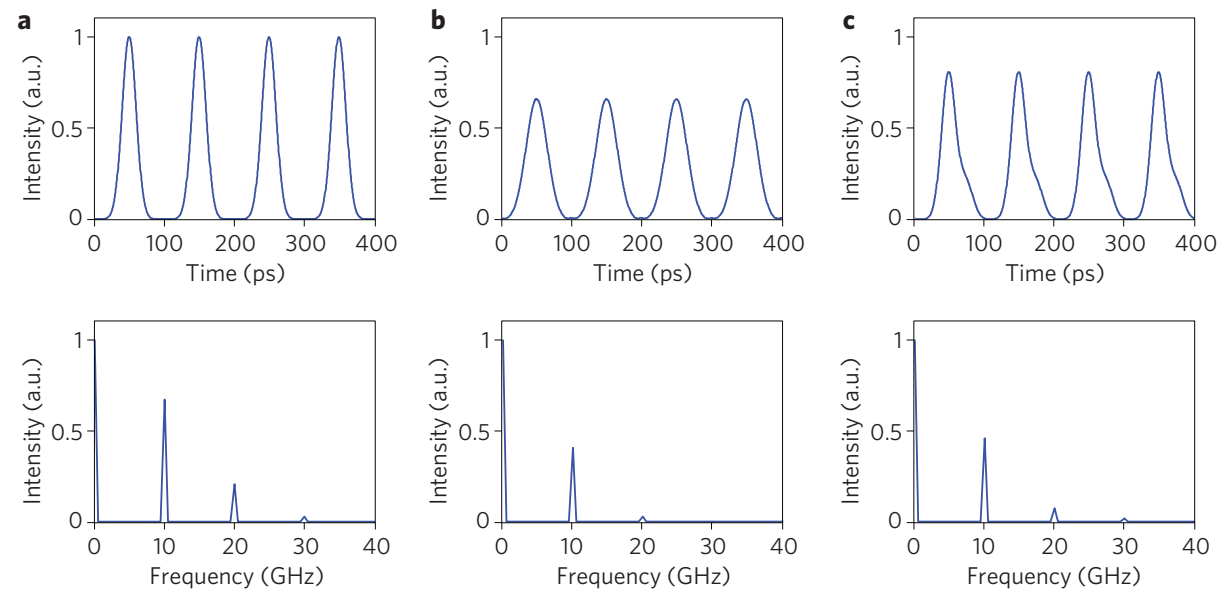